\title{
Surface Epitope Coverage Affects Binding Characteristics of Bisphenol-A Functionalized Nanoparticles in a Competitive Inhibition Assay
}

\author{
Yang Lu, ${ }^{1,2}$ Joshua Richard Peterson, ${ }^{3}$ Erwann Luais, ${ }^{3,4}$ \\ John Justin Gooding, ${ }^{3}$ and Nanju Alice Lee ${ }^{1}$ \\ ${ }^{1}$ School of Chemical Engineering and ARC Training Centre for Advanced Technologies in Food Manufacture, \\ University of New South Wales, Sydney, NSW 2052, Australia \\ ${ }^{2}$ Key Laboratory of Food Nutrition and Safety, Ministry of Education, Tianjin Key Laboratory of Food Nutrition and Safety, \\ Tianjin University of Science and Technology, Tianjin 300457, China \\ ${ }^{3}$ School of Chemistry and Australian Centre for NanoMedicine, University of New South Wales, Sydney, NSW 2052, Australia \\ ${ }^{4}$ GREMAN, François Rabelais University, Parc de Grandmont, 37200 Tours, France
}

Correspondence should be addressed to John Justin Gooding; justin.gooding@unsw.edu.au and Nanju Alice Lee; alice.lee@unsw.edu.au

Received 20 July 2015; Revised 28 September 2015; Accepted 29 October 2015

Academic Editor: Kimberly Hamad-Schifferli

Copyright (C) 2015 Yang Lu et al. This is an open access article distributed under the Creative Commons Attribution License, which permits unrestricted use, distribution, and reproduction in any medium, provided the original work is properly cited.

\begin{abstract}
The biomolecule interface is a key element in immunosensor fabrication, which can greatly influence the sensor performance. This paper explores the effects of surface epitope coverage of small molecule functionalized nanoparticle on the apparent affinity (avidity) of antibody in a competitive inhibition assay using bisphenol-A (BPA) as a model target. An unconventional two-antibody competitive inhibition ELISA (ci-ELISA) using thiolated BPA modified gold nanoparticles (cysBPAv-AuNP) as a competing reagent was devised for this study. It was shown that the antibody complexation with cysBPAv-AuNPs required a minimum number of surface epitopes on the nanoparticle to form a sufficiently strong interaction and reliable detection. The binding of cysBPAv-AuNP to anti-BPA antibodies, for limited antibody binding sites, was enhanced by a greater number of epitope-modified nanoparticles (cysBPAv-AuNP) as well as with higher epitope coverage. Increasing the molar concentration of epitope present in an assay enhanced the binding between anti-BPA antibodies and cysBPAv-AuNP. This implies that, to increase the limit of detection of a competitive inhibition assay, a reduced molar concentration of epitope should be applied. This could be achieved by either lowering the epitope coverage on each cysBPAv-AuNP or the assay molar concentration of cysBPAv-AuNP or both of these factors.
\end{abstract}

\section{Introduction}

Due to the size-dependent optical and electronic properties of gold nanoparticles (AuNPs), the volume of literature on their application in sensing is immense [1-3]. In electrochemical sensors, AuNPs have been used to enhance refractive index changes $[4,5]$, increase the surface-volume ratio, provide high conductivity, and accelerate electron transfer to a redox active species [6-8]. To fabricate AuNPs-based biosensors, AuNPs have been modified with short peptides or organic molecules $[8,9]$. The organic molecules could be a ligand or an epitope to which an antibody could specifically bind. The modification of AuNPs with small organic molecules is a construct with considerable potential, particularly in immunosensing. Amplification of analytical signals that are made possible by gold nanoparticles is even more important for small molecule detection than macromolecule detection. The antibody binding of small molecules to a biosensing interface is notoriously hard to detect otherwise. To date, however, the vast majority of studies employing organic molecule functionalized AuNPs are motivated towards detecting protein $[3,8,10]$ rather than small molecules such as pesticides, endocrine disruptors, and pharmaceutical or veterinary drugs.

The most relevant study where gold nanoparticles are used in immunosensing for detecting small molecules is 
by Taguchi et al. [11]. In that study, an analogue of the endocrine disruptor, bisphenol-A (BPA), was used to modify AuNPs for the fabrication of a competitive surface plasmon resonance (SPR) based sensor. This competitive assay for small molecules had a limit of detection of $0.1 \mathrm{mM}$ (equivalent to $22.8 \mathrm{mg} \mathrm{L}^{-1}$ ). The relevance of the Taguchi study for the present work is that AuNPs modified with small organic molecules are a central component in an immunoassay. We are interested in using organic modified nanoparticles in ELISA and as analogues of hapten-protein conjugates for the generation of antibodies. There have not been any studies in which gold nanoparticles modified with a small organic molecule epitope have been characterized using the standard tool of immunochemistry. The combination of ELISA and nanoparticles is potentially useful, not only as a rapid approach to characterizing the functionality of a nanoparticle as a sensing element $[6,10]$, but also as an assay reagent.

Small molecule analytes are typically quantified by a competitive inhibition format in an immunoassay [12]. Based on the law of mass action, assay sensitivity is proportional to the value of equilibrium constant (i.e., the amount of the antigen-antibody complex). In a competitive inhibition assay, there are two equilibrium constants to be considered; the equilibrium constant involving the antigen itself is denoted by $K_{a}$ and the other involving the labelled competing antigen (often referred to as hapten) is denoted by $K_{a^{*}}$, as illustrated in the equations below:

$$
\begin{gathered}
{[\mathrm{Ab}]+[\mathrm{Ag}] \underset{k_{2}}{\stackrel{k_{1}}{\leftrightarrows}}[\mathrm{AbAg}] \quad K_{a}=\frac{k_{1}}{k_{2}}=\frac{[\mathrm{AbAg}]}{[\mathrm{Ab}][\mathrm{Ag}]}} \\
{[\mathrm{Ab}]+\left[\mathrm{Ag}^{*}\right] \underset{k_{4}}{\stackrel{k_{3}}{\leftrightarrows}}\left[\mathrm{AbAg}^{*}\right] \quad K_{a^{*}}=\frac{k_{3}}{k_{4}}=\frac{\left[\mathrm{AbAg}^{*}\right]}{[\mathrm{Ab}]\left[\mathrm{Ag}^{*}\right]}}
\end{gathered}
$$

Assay sensitivity is predominantly influenced by two factors: (1) the relative affinity of an antibody between the target molecule $([\mathrm{Ag}])$ and the competing hapten $\left(\left[\mathrm{Ag}^{*}\right]\right)$ which is labelled with an enzyme for measurement and (2) the epitope density of the competing hapten coupled to an enzyme as a label $\left(K_{a}\right.$ versus $\left.K_{a^{*}}\right)$. For the first factor, selection of an appropriate hapten structure with a right linker for the enzyme conjugation is critical in achieving the greatest possible sensitivity by controlling the relative affinity of the antibody between the target molecule and the competing molecule $\left(K_{a}>K_{a^{*}}\right)$. For the second factor, the epitope density of the hapten-enzyme conjugate provides multivalence in order to enhance the binding affinity, particularly useful for the weak binding antibodies in a polyclonal population. This phenomenon has been well demonstrated in many immunoassays developed for small molecules such as endocrine disrupting chemicals, pesticides, and mycotoxins $[13,14]$. The concentration of the competing hapten in an assay influences the assay affinity (i.e., avidity) in a competitive immunoassay. The concentration of the competing hapten in an assay is generally determined as the concentration of the conjugate concentration rather than the concentration of hapten. This is because the epitope density of the hapten-enzyme conjugate is heterogeneous and could not be readily determined. Therefore, batch-to-batch variation is typical, making quality control of assay reagents such as hapten-enzyme conjugate somewhat difficult.

Nanoparticles can serve as a good platform for targeted functionalization with small molecule epitopes. The purpose of this paper is to demonstrate the application of AuNPs modified with small molecule epitopes for binding to antibodies in a competitive inhibition format. More importantly, the ability of the AuNPs to support multiple either homologous or heterologous epitopes means that more than one antibody can bind to the AuNPs in a manner reminiscent of a sandwich ELISA although the nature of the ELISA is a competitive inhibition. Given the inherent complexities of the interaction of surface epitopes with antibodies, however, which may be different then the biological conjugate (e.g., protein-hapten conjugates) in a competitive inhibition event, we sought to investigate factors that may affect the antibody-surface epitope interaction and the subsequent analytical performance in a competitive inhibition assay. A better understanding of quantitative relationship between structure and activity in terms of avidity relating to multivalent interaction in a competitive inhibition manner will provide information about the future design of targeted nanoparticles for immunosensing of small molecule analytes. In this study, the surface bound epitope is a thiolated bisphenol-A derivative and the antibodies used are anti-BPA antibodies we have described previously [15].

\section{Experimental}

2.1. Materials. 4,4-Bis(4-hydroxyphenyl)valeric acid (BPAvaleric acid), N-hydroxysuccinimide (NHS), N, $\mathrm{N}^{\prime}$-dicyclohexylcarbodiimide (DCC), dimethyl sulfoxide (DMSO), 3,3',5,5' -tetramethylbenzidine (TMB), Tween-20, and avidin-horseradish peroxidase (HRP) were purchased from Sigma-Aldrich (Sydney, Australia). Absolute ethanol (EtOH), methanol $(\mathrm{MeOH})$, and sulphuric acid were obtained from Ajax Finechem (Sydney, Australia). Disodium hydrogen phosphate, monosodium phosphate, and sodium chloride were sourced BDH Chemicals (Melbourne, Australia). MaxiSorp polystyrene 96-well plates were obtained from Nunc (Roskilde, Denmark). Ultrapure water was from either a Millipore Milli-Q Academic System $(18.2 \mathrm{M} \Omega \cdot \mathrm{cm})$ or a Sartorius arium 61316/611VF $(17.6 \mathrm{M} \Omega \mathrm{cm})$. Skim milk powder was purchased from a local supermarket (NSW, Australia). The preparation of the cysteamine-BPA-valerate ligand (cysBPAv), gold nanoparticles (AuNPs), anti-BPA antibodies (referred to as AbøBPA-V2\#4), and BPA-valerateBSA and the conjugation of antibodies and biotin (referred to as AbøBPA-V2\#4-biotin) were described previously $[14,15]$.

2.2. Instrumentation. An ELISA plate reader (SpectroMax M2) was obtained from Molecular Devices (Sunnyvale, USA). Centrifugation was performed using a Sigma 114 Laboratory Table Top Microcentrifuge $(16,163 \times \mathrm{g}$ for $15 \mathrm{~min}$ ). Nuclear magnetic resonance (NMR) measurements were performed on a Bruker Avance III $300 \mathrm{MHz}$. UV-Vis 
measurements were performed on a Varian Cary 50 Bio UVVisible spectrophotometer.

2.3. Modification of AuNPs. Based on modification of the AuNPs described previously [16], different volumes (13, $15,20,30$, and $60 \mu \mathrm{L})$ of $1 \mathrm{mmol} \mathrm{L}^{-1}$ of BPA modified compound, cysBPAv, in EtOH were added to $1 \mathrm{~mL}$ of the above AuNPs solution, and then the mixture was allowed to stand at room temperature overnight in the dark to synthesize cysBPAv-AuNP-160, cysBPAv-AuNP-190, cysBPAvAuNP-265, cysBPAv-AuNP-396, and cysBPAv-AuNP-801, respectively. After centrifugation $(16,163 \times \mathrm{g}$ for $15 \mathrm{~min})$, the pellet was resuspended in $100 \mu \mathrm{L} \mathrm{EtOH}$ and then diluted with $900 \mu \mathrm{L}$ of Milli-Q water. The number of cysBPAv ligands conjugated per nanoparticle depicted in parentheses (e.g., cysBPAv-AuNP-190 corresponds to particle cysBPAv-AuNP with 190 conjugated ligands) was calculated based on the indirect competitive ELISA (i-ELISA) results of the amount of unconjugated thiolated ligand.

2.4. Preparation of BPA Standard. Standard stock solution $\left(1 \times 10^{6} \mu \mathrm{g} \mathrm{L}^{-1}\right)$ of BPA was prepared by dissolving an appropriate amount of BPA in $\mathrm{MeOH}$. Working standard solutions $\left(0.51-10,000 \mu \mathrm{g} \mathrm{L}^{-1}\right)$ were prepared by diluting the stock solution in $10 \% \mathrm{EtOH} /$ phosphate buffered saline (PBS) just before use.

2.5. $i$-ELISA. The \% conjugation of cysBPAv to AuNP was determined by measuring the amount of unconjugated cysBPAv remaining in the supernatant by $\mathrm{i}$-ELISA. The i-ELISA was conducted as follows. BPA-valerate-BSA was immobilized onto a microplate at $10 \mu \mathrm{g} \mathrm{mL}^{-1}$. The microwell plate was washed three times with washing solution (0.05\% Tween-20) and blocked with $3 \%$ skim milk power in PBS ( $\mathrm{pH} 7.4$ ) for $1 \mathrm{~h}$. After washing the plate as previously described, the cysBPAv standard solutions and AboBPA-V2\#4 antiserum were added to the respective wells and the mixture was incubated for $1 \mathrm{~h}$. The plate was washed 4 times with washing solution, and the anti-rabbit IgG conjugate dissolved in PBS was added to all the wells and the mixture was incubated for $30 \mathrm{~min}$. After washing the plate five times, substrate solution (TMB) was added to all the wells to develop the color. The color reaction was stopped after $20 \mathrm{~min}$ by adding $50 \mu \mathrm{L}$ of $1.25 \mathrm{~mol} \mathrm{~L}^{-1}$ sulphuric acid into each well and the absorbance values of the wells were measured at $450 \mathrm{~nm}$. In this way, the more unconjugated cysBPAv are in solution, the less AbøBPAV2\#4 binds to the immobilized BPA-valerate-BSA and hence the lower absorbance after the color reaction is.

2.6. Two-Antibody Competitive Inhibition ELISA (ci-ELISA). Microwells were immobilized with AbøBPA-V2\#4 antibody at $10 \mu \mathrm{g} \mathrm{mL}^{-1}$. After washing the microwell plate three times with the washing solution, $1 \%$ soybean protein in PBS (SBPPBS, $\mathrm{pH}$ 7.4) was incubated in the wells for $1 \mathrm{~h}$. The plate was washed 3 times again. BPA standard solutions in 10\% $\mathrm{EtOH} / \mathrm{PBS}$ and cysBPAv-AuNPs in $10 \% \mathrm{EtOH} / \mathrm{PBS}$ were added to the respective wells and the mixture was incubated for $30 \mathrm{~min}$. The plate was washed again, and AbøBPA-V2\#4biotin in 10\% EtOH/PBS was added and incubated for $1 \mathrm{~h}$.
After washing the plate, avidin-HRP conjugate in PBS was added to the wells and incubated for $30 \mathrm{~min}$. The plate was washed 5 times this time to remove any unbound reagents and nanoparticles; then substrate solution (TMB) was added to all the wells to develop the color. The absorbance values were measured at $450 \mathrm{~nm}$ after the color reaction was stopped after 20 min by adding $50 \mu \mathrm{L}$ of $1.25 \mathrm{~mol} \mathrm{~L}^{-1}$ sulphuric acid (Figure 1).

\section{Results and Discussion}

3.1. Characterization of Functionalized Gold Nanoparticles with Different Epitope Coverage. The synthesis and characterization of unmodified AuNP were reported previously [16]. The average size of the unmodified AuNPs was determined to be $5.3 \pm 1.6 \mathrm{~nm}$ using the TEM images. The concentration of AuNPs solution was estimated to be $6.35 \times 10^{-8} \mathrm{~mol} \mathrm{~L}^{-1}$, which was calculated based on the extinction coefficient of the AuNPs of $7.20 \times 10^{6} \mathrm{M}^{-1} \mathrm{~cm}^{-1}$ [16]. The nanoparticles were modified with thiolated BPA via sulfhydryl exchange and denoted by cysBPAv-AuNPs. The estimated number of cysBPAv ligands conjugated per nanoparticle is appended to the particle name (e.g., cysBPAv-AuNP-190 corresponds to particle cysBPAv-AuNP with 190 conjugated ligands) and was calculated based on the indirect competitive ELISA (i-ELISA) results of the amount of unconjugated thiolated ligand as described in Section 2.5. The modified particles with different surface epitope coverage (cysBPAv-AuNP-163, cysBPAvAuNP-190, cysBPAv-AuNP-265, cysBPAv-AuNP-396, and cysBPAv-AuNP-801) were estimated to have the epitope coverage of $3.0 \times 10^{-10}, 3.6 \times 10^{-10}, 4.9 \times 10^{-10}, 7.4 \times 10^{-10}$, and $15.0 \times 10^{-10} \mathrm{~mol} \mathrm{~cm}^{-2}$, respectively, or an average of 163 , 190, 265, 396, and 801 epitopes per particle (Table 1).

3.2. Characterization of cysBPAv-AuNPs Using i-ELISA. The surface epitope coverage affecting the avidity of the AbøBPAV2\#4 antibody for the nanoparticles modified with the 5 different epitope coverage was studied using the indirectELISA at the nanoparticle molar concentrations in the range between $3.7 \times 10^{-10}$ and $4.7 \times 10^{-13} \mathrm{~mol} \mathrm{~L}^{-1}$. As the StokesEinstein radius of $\operatorname{IgG}(56 \AA)$ is relative to the average diameter of AuNP ( $5 \mathrm{~nm}$ ), we made an assumption that only one cysBPAv-AuNP will bind to one antibody at each incubation step largely due to the steric constraints [15, 17]. Upon binding to the immobilized antibody, the remaining cysBPAv epitopes on the nanoparticle are potentially free to bind to the AboBPA-V2\#4-biotin conjugate as the detection antibody much like a sandwich-like configuration. The antibodyepitope binding was determined using a HRP-streptavidin conjugate that complexes with the biotinylated detection antibody. The use of avidin-biotin system in this assay proved to lower the nonspecific binding as well as allowing for signal amplification for more reliable measurement (data not shown).

The surface epitope coverage was estimated to span a range from $3.0 \times 10^{-10}$ to $15 \times 10^{-10} \mathrm{~mol} \mathrm{~cm}^{-2}$ (Table 1), representing an approximately fivefold change in the epitope molar concentrations. As illustrated in Figure 2, the 
TABLE 1: The epitope coverage and $K_{d}$ of each cysBPAv-AuNP.

\begin{tabular}{lcccc}
\hline CysBPAv-AuNP & Epitope coverage $\left(\mathrm{mol} \mathrm{cm}^{-2}\right)$ & Surface epitopes per AuNP & \% Surface coverage & $K_{d}\left(\times 10^{-8} \mathrm{~mol} \mathrm{~L}^{-1}\right)$ \\
\hline CysBPAv-AuNP-163 & $3.0 \times 10^{-10}$ & 163 & 20 & - \\
CysBPAv-AuNP-190 & $3.6 \times 10^{-10}$ & 190 & 24 & $6.8 \pm 2.9$ \\
CysBPAv-AuNP-265 & $4.9 \times 10^{-10}$ & 265 & 33 & $2.3 \pm 0.9$ \\
CysBPAv-AuNP-396 & $7.4 \times 10^{-10}$ & 396 & 50 & $1.3 \pm 0.4$ \\
CysBPAv-AuNP-801 & $15.0 \times 10^{-10}$ & 801 & 100 & $0.48 \pm 0.06$ \\
\hline
\end{tabular}

- cannot be estimated due to high variability in data.

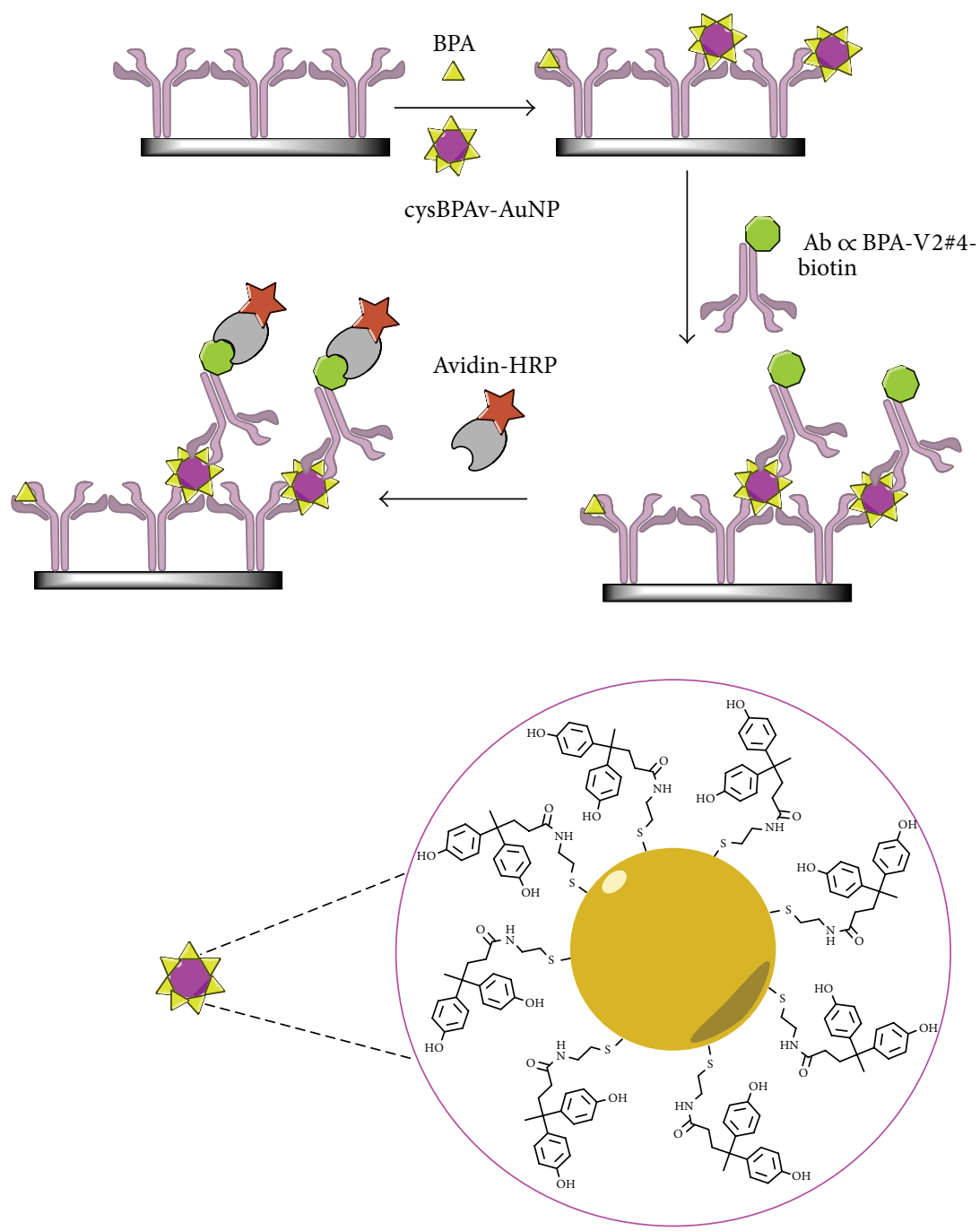

FIgURE 1: The configuration of ci-ELISA.

absorbance increased with increasing epitope coverage on the nanoparticles. Nanoparticles with lower epitope coverage required higher molar particle concentrations to reach the same absorbance value as those with higher epitope coverage which required lower molar particle concentrations. For instance, the absorbance generated using $3 \times 10^{-10} \mathrm{~mol} \mathrm{~L}^{-1}$ cysBPAv-AuNP-163 (i.e., particle with lower epitope coverage) was the same as using $8 \times 10^{-11} \mathrm{~mol} \mathrm{~L}^{-1}$ cysBPAvAuNP-801 (i.e., particle with higher epitope coverage). This indicated that the interaction between cysBPAv epitopes and antibodies particularly with the biotinylated antibody was facilitated by having multiple epitopes on the nanoparticles, which enhanced the binding strength (avidity). Based on the calculated epitope coverage, minimum of approximately 160 epitopes per particle (estimated to be roughly $20 \%$ surface coverage) was needed to generate a detectable and reproducible signal. Below this number, the antibody binding showed large deviation in the measurement (data not shown).

The surface epitope coverage also affected the molar concentrations of nanoparticles at which the binding event 


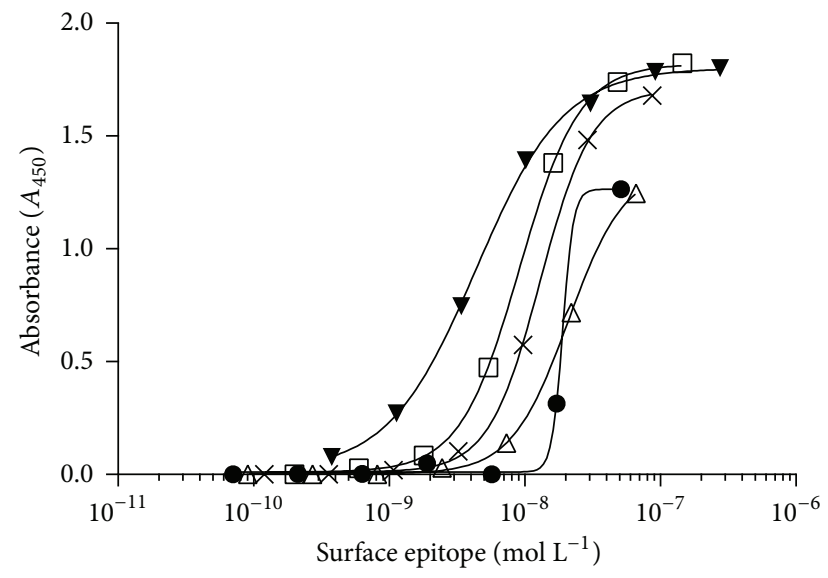

FIGURE 2: The dose-response relationship between molar concentrations of surface epitopes on cysBPAv-AuNPs and AbøBPA-V2\#4 $\left(1 \times 10^{4} \mu \mathrm{g} \mathrm{L}^{-1}\right) . \bullet=$ cysBPAv-AuNP-163; $\triangle$ = cysBPAv-AuNP-190; $\times=$ cysBPAv-AuNP-265; $\square=$ cysBPAv-AuNP-396; $\boldsymbol{\nabla}=$ cysBPAvAuNP-801.

could be detectable, and the range of molar concentrations of nanoparticles showed strong antibody binding. The equilibrium dissociation constants $\left(K_{d}\right)$ of cysBPAv-AuNP190, cysBPAv-AuNP-265, cysBPAv-AuNP-396, and cysBPAvAuNP-801 were $6.8 \pm 2.9 \times 10^{-8}, 2.3 \pm 0.9 \times 10^{-8}, 1.3 \pm 0.4 \times$ $10^{-8}$, and $0.48 \pm 0.06 \times 10^{-8} \mathrm{~mol} \mathrm{~L}^{-1}$ (Table 1). The $K_{d}$ for cysBPAv-AuNP-163 could not be estimated due to the large variation in the binding data. The decrease in $K_{d}$ values with increase in surface epitope coverage clearly demonstrated that multivalent surface ligand does increase the affinity of antibody. The minimum molar nanoparticle concentration of cysBPAv-AuNP-163 showing the antibody binding was $1.0 \times 10^{-10} \mathrm{~mol} \mathrm{~L}^{-1}$. The cysBPAv-AuNP-801 nanoparticles, which had five times more epitopes than cysBPAv-AuNP163 , showed the antibody binding at the molar nanoparticle concentration 200 times lower than that of cysBPAvAuNP-163. Increasing surface epitope coverage of functionalized nanoparticles decreased the molar concentration of nanoparticle required for the antibody binding exponentially (Figure 2).

In short, these results show the importance of surface epitope coverage in providing more efficient multivalent interaction between antibody and surface epitopes in enhancing the assay avidity. Such findings are also observed in the previous studies using noncompetitive assays [18-20].

3.3. ci-ELISA under Different Molar Concentrations of $c y s B P A v-A u N P-265$. In order to study the relationship between surface epitope coverage (on nanoparticles) and multivalent interaction with an antibody, a competitive inhibition enzyme-linked immunosorbent assay (ci-ELISA) using two BPA-specific antibodies was devised. In this assay, the free BPA and cysBPAv-AuNP were allowed to compete with each other to bind to the immobilized antibody. The signal was generated via the second biotinylated antibody binding to the bound cysBPAv-AuNP. Avidin-HRP/TMB substrate system was added to generate the colorimetric signal. If free BPA was bound to an antibody, then this binding site was no longer free to bind to the cysBPAv-AuNP and hence does not generate color. CysBPAv-AuNP, on the other hand, had multivalent epitopes conjugated to the particle surface, some of which would still be available to bind to the biotinylated antibody. Therefore, the ci-ELISA devised in this manner could be used to quantify free BPA based on the degree of cysBPAv-AuNP competitively bound to the immobilized antibody relative to the free BPA. As for a competitive assay, the color development is inversely proportional to the concentration of free BPA.

The three factors selected for the study were the surface epitope coverage, the molar concentration of epitope in an assay, and the molar concentration of particle (i.e., cysBPAvAuNPs). In an ELISA, both the epitope coverage of haptenprotein conjugates and concentration of epitope in an assay influence the linear detection range and an $\mathrm{IC}_{50}$. Thus, the epitope coverage of competing hapten-protein conjugate and its quantity in an assay are typically optimised to yield the lowest $\mathrm{IC}_{50}$. So it was relevant to study these factors with nanoparticles functionalized with small molecule epitopes. Nanoparticles serve as carriers of epitopes in this study; however, their physical structures may interfere with antibodyantigen interaction. Whether the diffusion of nanoparticle, which is dependent on their concentrations, influences the antibody binding to the surface epitope in a competitive assay has yet to be explored.

In the first experiment, the surface epitope coverage was fixed by using cysBPAv-AuNP-265 to investigate the effects of the molar concentration of nanoparticles and the molar concentration of epitopes in an assay on the competitive binding. The three molar concentrations of nanoparticles $(6.6 \times$ $10^{-10} \mathrm{~mol} \mathrm{~L}^{-1}, 3.3 \times 10^{-10} \mathrm{~mol} \mathrm{~L}^{-1}$, and $1.3 \times 10^{-10} \mathrm{~mol} \mathrm{~L}^{-1}$ ) selected were above the minimum particle concentration required for generating detectable signal in the indirect ELISA as determined above $\left(1.2 \times 10^{-11} \mathrm{~mol} \mathrm{~L}^{-1}\right.$ of cysBPAvAuNP-265).

From the results (Figures 3(a) and 3(b) and Table 2), a typical sigmoidal curve of the competitive inhibition assay was observed, showing a decrease in absorbance with an increase in free BPA concentration. This indicated that the cysBPAvAuNP behaved much like a multivalent hapten-protein conjugate in an immunoassay. As shown in Figure 3(b) and Table 2 , the $\mathrm{IC}_{50}$ value decreased eightfold (from $8 \mu \mathrm{mol} \mathrm{L}{ }^{-1}$ to $\left.1.2 \mu \mathrm{mol} \mathrm{L}^{-1} \mathrm{BPA}\right)$ when the molar concentration of cysBPAv-AuNPs was reduced roughly 5 -fold (from $6.6 \times 10^{-10}$ to $\left.1.3 \times 10^{-10} \mathrm{~mol} \mathrm{~L}^{-1}\right)$. When the molar concentration of cysBPAv-AuNPs decreased from $6.6 \times 10^{-10} \mathrm{~mol} \mathrm{~L}^{-1}$ to $1.3 \times$ $10^{-10} \mathrm{~mol} \mathrm{~L}-1$, the affinity constants $\left(K_{a}\right)$ for the respective molar concentration of surface epitopes were $0.13 \pm 0.02$, $0.23 \pm 0.03$, and $0.62 \pm 0.09 \mathrm{~L} \mathrm{~mol}^{-1}$, showing the binding affinity of antibody for BPA increased with the decrease of the surface epitopes. This result indicates that the molar concentration of nanoparticle and the molar concentration of epitope in an assay had a significant influence on the linear detection range and limit of detection in a competitive inhibition assay of this type. The assay sensitivity as measured by the slope of the standard curves was not significantly 
TABLE 2: Assay parameters and calculated affinity constant derived from Figure 3.

\begin{tabular}{|c|c|c|c|}
\hline Nanoparticle & $265(\bullet)$ & $265(\square)$ & $265(\mathbf{\Delta})$ \\
\hline Particle number $\left(\mathrm{mol} \mathrm{L}^{-1}\right)$ & $6.6 \times 10^{-10}$ & $3.3 \times 10^{-10}$ & $1.3 \times 10^{-10}$ \\
\hline Molar concentration of surface epitope $\left(\mathrm{mol} \mathrm{L}^{-1}\right)$ & $1.7 \times 10^{-7}$ & $9.0 \times 10^{-8}$ & $3.0 \times 10^{-8}$ \\
\hline Slope from Figure 3(b) & $1.1 \pm 0.11$ & $0.87 \pm 0.07$ & $0.88 \pm 0.13$ \\
\hline $\mathrm{IC}_{50}(\mu \mathrm{mol} \mathrm{L}-1)$ & $8.0 \pm 1.5$ & $4.4 \pm 1.2$ & $1.2 \pm 1.2$ \\
\hline Affinity constant $\left(K_{a}, \mu \mathrm{mol}^{-1}\right)$ & $0.13 \pm 0.02$ & $0.23 \pm 0.03$ & $0.62 \pm 0.09$ \\
\hline Linear detection range ${ }^{*}\left(\mu \mathrm{mol} \mathrm{L}{ }^{-1}\right)$ & $1.9-30.2$ & $0.9-18.6$ & $0.2-5.6$ \\
\hline
\end{tabular}

${ }^{*} 20-80 \%$ of the $\% I$ curve.

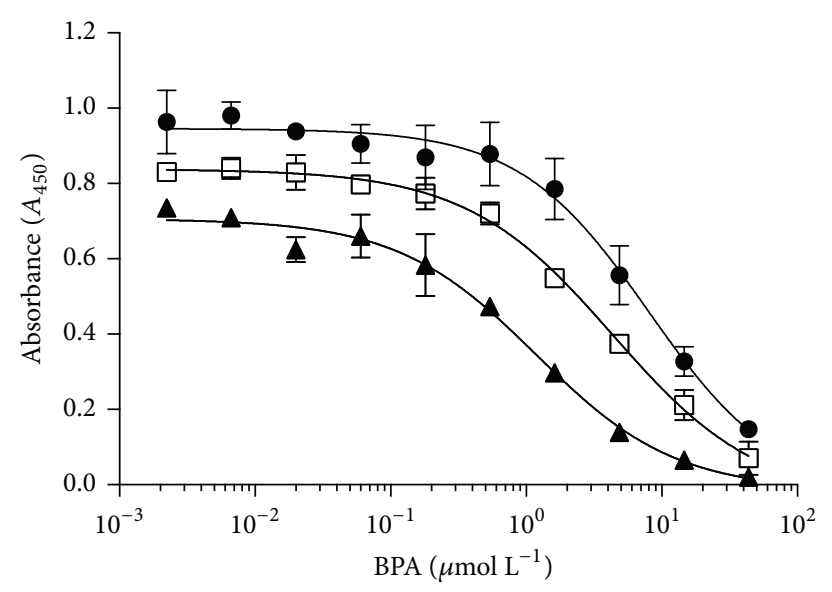

(a)

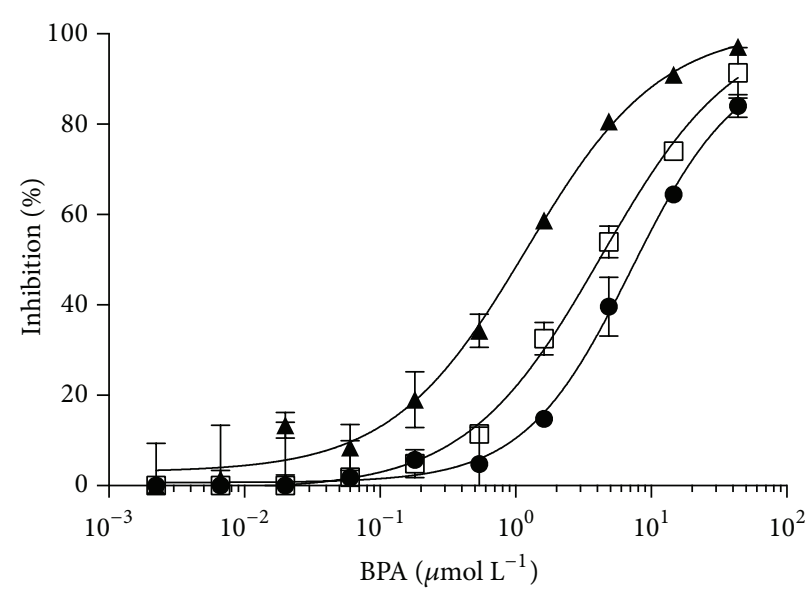

(b)

FIgURE 3: Dose-response curves of the ci-ELISA under the same epitope coverage. The absorbance curve (a) and inhibition curve using the molar concentration of cysBPAv-AuNP in an assay (b). $\bullet=6.6 \times 10^{-10} \mathrm{~mol} \mathrm{~L}^{-1}$ cysBPAv-AuNP-265 (molar concentration of epitope in an assay: $\left.1.70 \times 10^{-7} \mathrm{~mol} \mathrm{~L}^{-1}\right)$; $\square=3.3 \times 10^{-10} \mathrm{~mol} \mathrm{~L}^{-1}$ cysBPAv-AuNP-265 (molar concentration of epitope in an assay: $\left.9.00 \times 10^{-8} \mathrm{~mol} \mathrm{~L}{ }^{-1}\right) ; \boldsymbol{\Delta}=$ $1.3 \times 10^{-10}$ mol cysBPAv-AuNP-265 L $\mathrm{L}^{-1}$ (molar concentration of epitope in an assay: $4.00 \times 10^{-8} \mathrm{~mol} \mathrm{~L}^{-1}$ ).

influenced by the concentration of particles or epitopes. This is consistent with the assumption that AuNPs serve as a carrier for epitopes but do not participate in the binding process themselves.

3.4. ci-ELISA under the Same Molar Concentration of cysBPAv-AuNP-190, cysBPAv-AuNP-396, and cysBPAv$A u N P-801$. In a second set of experiments, cysBPAvAuNP-190, cysBPAv-AuNP-396, and cysBPAv-AuNP-801 were selected to study the effects of surface epitope coverage and the molar concentration of epitope in an assay without changing the amount of particles. The nanoparticle concentration was fixed at $2.1 \times 10^{-10} \mathrm{~mol} \mathrm{~L}^{-1}$. Consequently, the molar concentrations of the surface epitope in an assay changed fourfold $\left(4.0 \times 10^{-8} \mathrm{~mol} \mathrm{~L}^{-1}\right.$ for cysBPAv-AuNP190, $8.0 \times 10^{-8} \mathrm{~mol} \mathrm{~L}^{-1}$ for cysBPAv-AuNP-396, and $1.7 \times$ $10^{-7} \mathrm{~mol} \mathrm{~L}^{-1}$ for cysBPAv-AuNP-801).

It was noted that, at lower epitope concentration or lower surface epitope coverage, less free BPA was required to compete with the nanoparticles for antibody binding sites (Figure 4 and Table 3 ). That is, the $\mathrm{IC}_{50}$ decreased with a decrease in surface epitope coverage as did the linear detection range. Naturally, of course, this also means the molar concentration of the surface epitope also showed dose dependent effects. However, in contrast to the concentration of nanoparticles discussed in Section 3.4, the sensitivity was affected by the surface epitope coverage and reduced at higher surface epitope coverage as evidenced by the lower slope of the cysBPAv-AuNP-801 dose-response curve. The affinity constants of the antibody for cysBPAv-AuNP-190, cysBPAvAuNP-396, and cysBPAv-AuNP-801 decreased with increasing surface epitopes (Figure 4 and Table 3 ). These results indicated that the binding affinity of antibody to the surface epitope was likely to be dominated by the concentration of particles. Both surface epitope coverage and the molar concentration of epitope in an assay influenced the apparent sensitivity. It was not possible, however, to distinguish which of the two factors influenced this parameter more strongly.

3.5. ci-ELISA with the Same Molar Concentration of Epitope in an Assay of cysBPAv-AuNP-190, cysBPAv-AuNP-396, and cysBPAv-AuNP-801. Finally, in the third set of experiments, the molar concentration of epitope in an assay was fixed at $1.01 \times 10^{-7} \mathrm{~mol} \mathrm{~L}^{-1}$ in order to compare the effects of the surface epitope coverage and the molar concentration of particle in assay performance. The selected cysBPAvAuNP, therefore, exhibited different particle molar concentrations. The cysBPAv-AuNP with the lowest surface epitope coverage had the highest molar concentration of particle in an assay: cysBPAv-AuNP-190 at particle concentration 
TABLE 3: Assay parameters and calculated affinity constant derived from Figure 4.

\begin{tabular}{lccc}
\hline Nanoparticle & $190(\bullet)$ & $396(\square)$ & $801(\mathbf{\bullet})$ \\
\hline Particle number $\left(\mathrm{mol} \mathrm{L}^{-1}\right)$ & $2.1 \times 10^{-10}$ & $2.1 \times 10^{-10}$ & $2.1 \times 10^{-10}$ \\
Molar concentration of surface epitope $\left(\mathrm{mol} \mathrm{L}^{-1}\right)$ & $4.0 \times 10^{-8}$ & $8.0 \times 10^{-8}$ & $1.7 \times 10^{-7}$ \\
Slope from Figure $4(\mathrm{~b})$ & $0.68 \pm 0.08$ & $0.81 \pm 0.10$ & $0.36 \pm 0.14$ \\
$\mathrm{IC}_{50}(\mu \mathrm{mol} \mathrm{L}$ \\
Affinity constant $\left(K_{a}, \mu \mathrm{mol}^{-1}\right)$ & $0.7 \pm 1.2$ & $1.8 \pm 1.2$ & $20.0 \pm 15.4$ \\
Linear detection range $\left(\mu \mathrm{mol} \mathrm{L}^{-1}\right)$ & $1.1 \pm 0.2$ & $0.55 \pm 0.08$ & $0.34 \pm 0.10$ \\
\hline
\end{tabular}

* $20-80 \%$ of the $\% I$ curve.

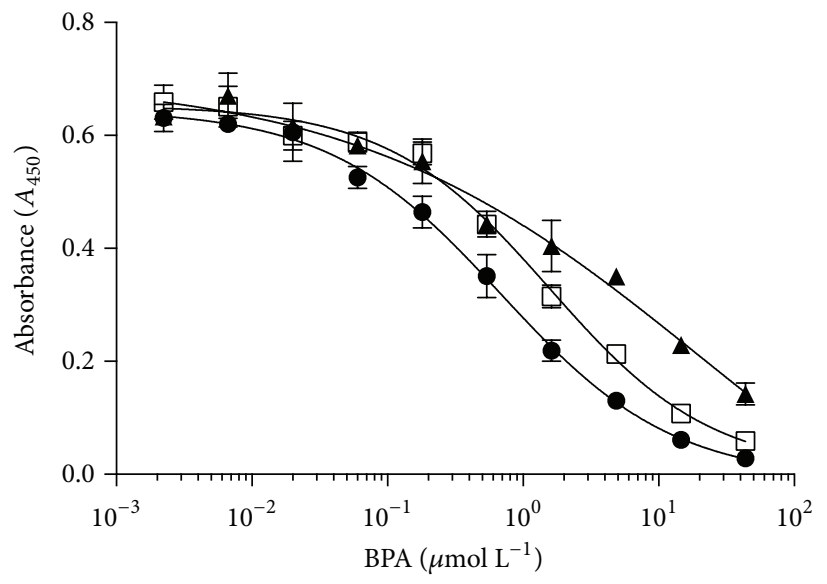

(a)

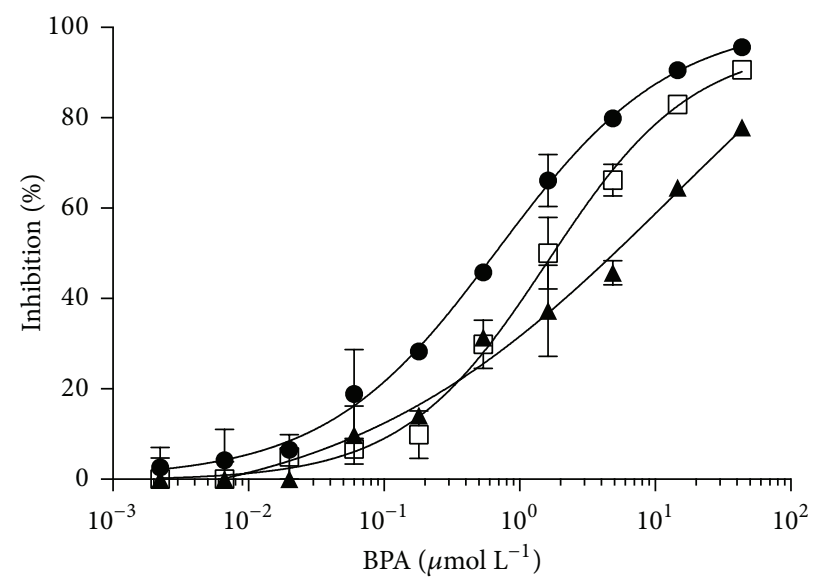

(b)

FIGURE 4: Dose-response curves of the ci-ELISA under the same molar concentration of particle in an assay. Absorbance curve (a) and inhibition curve (b) of the c-ELISA conducted using the same molar concentration cysBPAv-AuNP. $\bullet=2.1 \times 10^{-10}$ mol cysBPAv-AuNP$190 \mathrm{~L}^{-1}$ (the concentration of epitope in an assay: $4.0 \times 10^{-8} \mathrm{~mol} \mathrm{~L}^{-1}$ ); $\square=2.1 \times 10^{-10}$ mol cysBPA-AuNP-396 $\mathrm{L}^{-1}$ (the concentration of epitope in an assay: $\left.8.0 \times 10^{-8} \mathrm{~mol} \mathrm{~L}^{-1}\right) ; \boldsymbol{\Lambda}=2.1 \times 10^{-10} \mathrm{~mol}$ cysBPA-AuNP-801 L ${ }^{-1}$ (the concentration of epitope in an assay: $1.7 \times 10^{-7} \mathrm{~mol} \mathrm{~L}^{-1}$ ).

of $5.3 \times 10^{-10} \mathrm{~mol} \mathrm{~L}^{-1}$, cysBPAv-AuNP-396 at the particle concentration of $2.6 \times 10^{-10} \mathrm{~mol} \mathrm{~L}^{-1}$, and cysBPAv-AuNP-801 at the particle concentration of $1.3 \times 10^{-10} \mathrm{~mol} \mathrm{~L}^{-1}$.

As shown in Figure 5 and Table 4, the nanoparticles with different surface epitope coverage, particularly cysBPAvAuNP-190 and cysBPAv-AuNP-396, exhibited similar maximum absorbance values (i.e., absorbance at saturation), sensitivities, and $\mathrm{IC}_{50}$ values. The affinity constants of these nanoparticles at the same molar surface epitope concentration had no significant difference. The almost overlapping of the dose-response curves suggested that the molar concentration of nanoparticles probably had little effects on the competitive inhibition between free BPA and cysBPAvAuNP for the antibody binding. This result again supports the assertion that the AuNPs are simply carriers for the epitopes and it is the epitope concentration and surface coverage that are the important variables for the assay sensitivity.

\section{Conclusions}

Interaction between an antibody and multivalent surface epitopes is a means to enhance antibody avidity for weak binding antigens. The effects of multivalent interaction in the competitive inhibition assay, however, have not previously been studied. In this study, we explored the interaction between an antibody and multivalent surface epitopes of a small molecule in a competitive inhibition assay. The competitive inhibition assay using a 96-microwell platform was devised using the two-antibody approach with the avidinbiotin signal enhancement system. Surface epitopes with varying epitope densities were synthesized by functionalizing AuNPs with various quantities of cysBPAv to yield surface coverage between 163 and 801 epitopes per nanoparticle.

The surface epitope coverage influenced the antibody avidity which was increased with higher surface epitope coverage. There was minimum surface epitope coverage which was required to give reliable antibody-epitope interaction for detection, and this value should be determined for each different platform. In this study, the minimum epitope coverage was estimated to be 163 epitopes per nanoparticle which was equivalent to $20 \%$ coverage. Higher surface epitopes provided stronger and more consistent interaction between antibody and surface epitopes.

The three different sets of competitive inhibition experiments conducted suggested that all three studied factors (i.e., surface epitope coverage, assay molar nanoparticle concentration, and assay molar concentration of epitope) affected the assay affinity, but each to different degree, and these factors were related with one another. The surface epitope coverage was important in increasing the avidity 
TABLE 4: Assay parameters and calculated affinity constant derived from Figure 5.

\begin{tabular}{lccc}
\hline Nanoparticle & $190(\bullet)$ & $396(\square)$ & $801(\mathbf{\Delta})$ \\
\hline Particle number $\left(\mathrm{mol} \mathrm{L}^{-1}\right)$ & $5.3 \times 10^{-10}$ & $2.6 \times 10^{-10}$ & $1.3 \times 10^{-10}$ \\
Molar concentration of surface epitope $\left(\mathrm{mol} \mathrm{L}^{-1}\right)$ & $1.0 \times 10^{-7}$ & $1.0 \times 10^{-7}$ & $1.0 \times 10^{-7}$ \\
Slope from Figure 5(b) & $0.65 \pm 0.11$ & $0.62 \pm 0.07$ & $1.0 \pm 0.13$ \\
$\mathrm{IC}_{50}\left(\mu \mathrm{mol} \mathrm{L}^{-1}\right)$ & $3.6 \pm 1.4$ & $4.7 \pm 1.6$ & $2.8 \pm 1.3$ \\
Affinity constant $\left(K_{a}, \mu \mathrm{mol}^{-1}\right)$ & $0.30 \pm 0.05$ & $0.27 \pm 0.04$ & $0.33 \pm 0.05$ \\
Linear detection range $\left(\mu \mathrm{mol} \mathrm{L}^{-1}\right)$ & $0.47-24.6$ & $0.74-40.7$ & $0.52-43.7$ \\
\hline
\end{tabular}

${ }^{*} 20-80 \%$ of the $\% I$ curve.

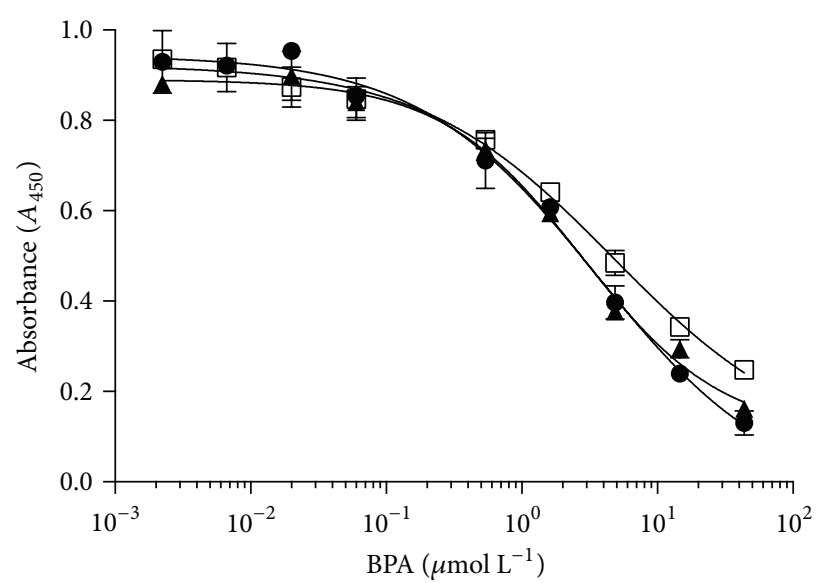

(a)

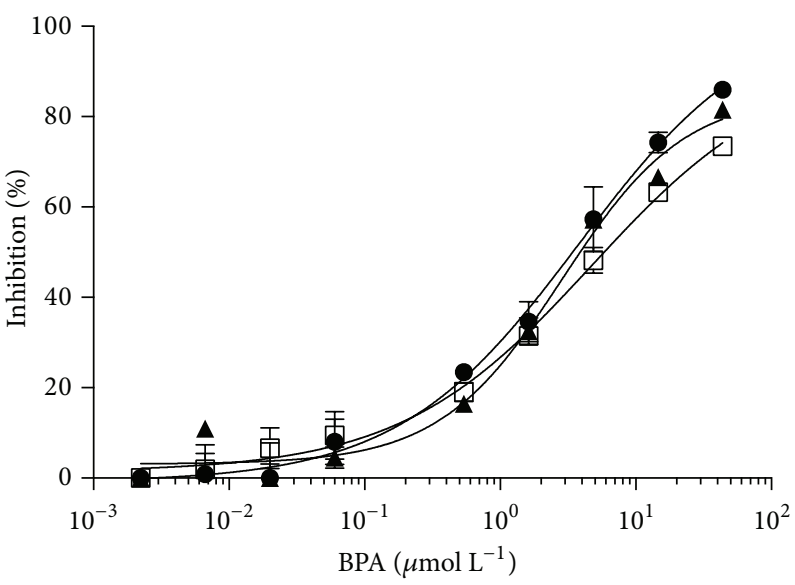

(b)

FIgURE 5: Dose-response curves of the ci-ELISAs under the same molar concentration of epitope in an assay. Absorbance curve (a); inhibition curve (b). $\bullet$ = the molar concentration of cysBPAv-AuNP-190 is $5.3 \times 10^{-10} \mathrm{~mol} \mathrm{~L}^{-1}$ (the molar concentration of epitope in an assay: $1.0 \times$ $10^{-7} \mathrm{~mol} \mathrm{~L}^{-1}$ ); $\square=2.6 \times 10^{-10} \mathrm{~mol}$ cysBPAv-AuNP-396 L ${ }^{-1}$ (the molar concentration of epitope in an assay: $1.0 \times 10^{-7} \mathrm{~mol} \mathrm{~L}^{-1}$ ); $\mathbf{\Delta}=1.3 \times$ $10^{-10}$ mol cysBPAv-AuNP-801 L ${ }^{-1}$ (the molar concentration of epitope in an assay: $1.0 \times 10^{-7} \mathrm{~mol} \mathrm{~L}^{-1}$ ).

via multivalent interaction between antibody and surface epitopes. The surface coverage of epitopes per nanoparticles is, in effect, a way of increasing the local concentration of the epitope in the vicinity of the antibody such that the equilibrium is biased to form a complex as well as influencing an $\mathrm{IC}_{50}$. The assay molar concentration of epitope was the most influential factor that determined the linear detection range and an $\mathrm{IC}_{50}$ of the competitive inhibition assay. Of the three factors, the assay molar nanoparticle concentration is the dominant factor of the affinity constant of antibody binding to the surface epitopes, while it also had the least effect on the assay sensitivity as long as the molar nanoparticle concentration in an assay was within the ranges of nanoparticle stability and below the saturation point of antibody binding sites.

This study showed that small epitope functionalized nanoparticles behave much like hapten-protein conjugates in a competitive inhibition assay, which also allowed precise control of surface chemistry. As indicated by the results of this study, nanoparticles with optimum surface epitope coverage are critical for the fabrication of immunosensors based on a competitive inhibition format. Additionally, the two-antibody competitive inhibition assay devised in this study was determined to be a simple and useful tool for characterizing targeted nanoparticles for the competitive inhibition assay.

\section{Ethical Approval}

All institutional and national guidelines for the care and use of laboratory animals were followed. The procedure used for raising polyclonal antibody was approved by the UNSW Animal Ethics Committee.

\section{Conflict of Interests}

The authors declare that there is no conflict of interests regarding the publication of this paper.

\section{Acknowledgments}

The authors express their thanks to the CSIRO Flagship Collaborative Research Program for financial support. Yang $\mathrm{Lu}$ is grateful for the CSIRO Flagship Scholarship.

\section{References}

[1] K. Saha, S. S. Agasti, C. Kim, X. Li, and V. M. Rotello, "Gold nanoparticles in chemical and biological sensing," Chemical Reviews, vol. 112, no. 5, pp. 2739-2779, 2012.

[2] S. Zeng, K.-T. Yong, I. Roy, X.-Q. Dinh, X. Yu, and F. Luan, "A review on functionalized gold nanoparticles for biosensing applications," Plasmonics, vol. 6, no. 3, pp. 491-506, 2011. 
[3] Y. Li, H. J. Schluesenerb, and S. Xu, "Gold nanoparticle-based biosensors," Gold Bulletin, vol. 43, no. 1, pp. 29-41, 2010.

[4] G. Liu, Y. Zhang, and W. Guo, "Covalent functionalization of gold nanoparticles as electronic bridges and signal amplifiers towards an electrochemical immunosensor for botulinum neurotoxin type A," Biosensors and Bioelectronics, vol. 61, pp. 547$553,2014$.

[5] A. C. Templeton, J. J. Pietron, R. W. Murray, and P. Mulvaney, "Solvent refractive index and core charge influences on the surface plasmon absorbance of alkanethiolate monolayerprotected gold clusters," Journal of Physical Chemistry B, vol. 104, no. 3, pp. 564-570, 2000.

[6] G. Z. Liu, S. G. Iyengar, and J. J. Gooding, "An amperometric immunosensor based on a gold nanoparticle-diazonium salt modified sensing interface for the detection of HbAlc in human blood," Electroanalysis, vol. 25, no. 4, pp. 881-887, 2013.

[7] H.-E. Lee, Y. O. Kang, and S.-H. Choi, "Electrochemical-DNA biosensor development based on a modified carbon electrode with gold nanoparticles for influenza A (H1N1) detection: effect of spacer," International Journal of Electrochemical Science, vol. 9, pp. 6793-6808, 2014.

[8] H. Liu, R. Malhotra, M. W. Peczuh, and J. F. Rusling, "Electrochemical immunosensors for antibodies to peanut allergen Ara h2 using gold nanoparticle-peptide films," Analytical Chemistry, vol. 82, no. 13, pp. 5865-5871, 2010.

[9] E. Boisselier and D. Astruc, "Gold nanoparticles in nanomedicine: preparations, imaging, diagnostics, therapies and toxicity," Chemical Society Reviews, vol. 38, no. 6, pp. 1759-1782, 2009.

[10] V. Mani, B. V. Chikkaveeraiah, V. Patel, J. S. Gutkind, and J. F. Rusling, "Ultrasensitive immunosensor for cancer biomarker proteins using gold nanoparticle film electrodes and multienzyme-particle amplification," ACS Nano, vol. 3, no. 3, pp. 585-594, 2009.

[11] Y. Taguchi, E. Takano, and T. Takeuchi, "SPR sensing of bisphenol A using molecularly imprinted nanoparticles immobilized on slab optical waveguide with consecutive parallel $\mathrm{Au}$ and $\mathrm{Ag}$ deposition bands coexistent with bisphenol A-immobilized $\mathrm{Au}$ nanoparticles," Langmuir, vol. 28, no. 17, pp. 7083-7088, 2012.

[12] R. C. Beier and L. H. Stanker, "Introduction to immunoassays for residue analysis: concepts, formats, and applications," ACS Symposium Series, vol. 621, 1996.

[13] R. C. Sinha, M. E. Savard, and R. Lau, "Production of monoclonal antibodies for the specific detection of deoxynivalenol and 15-acetyldeoxynivalenol by ELISA," Journal of Agricultural and Food Chemistry, vol. 43, no. 6, pp. 1740-1744, 1995.

[14] Y. Lu, J. R. Peterson, J. J. Gooding, and N. A. Lee, "Development of sensitive direct and indirect enzyme-linked immunosorbent assays (ELISAs) for monitoring bisphenol-A in canned foods and beverages," Analytical and Bioanalytical Chemistry, vol. 403, no. 6, pp. 1607-1618, 2012.

[15] J. R. Peterson, Y. Lu, E. Luais, N. A. Lee, and J. J. Gooding, "Demonstrating the use of bisphenol a-functionalised gold nanoparticles in immunoassays," Australian Journal of Chemistry, vol. 66, no. 6, pp. 613-618, 2013.

[16] W. Haiss, N. T. K. Thanh, J. Aveyard, and D. G. Fernig, "Determination of size and concentration of gold nanoparticles from UV-Vis spectra," Analytical Chemistry, vol. 79, no. 11, pp. 4215-4221, 2007.

[17] R. J. M. D. Mullins, M. A. B. A. Malias, and R. W. B. S. Hudgens, "Isoproterenol inhibits the increase in microvascular membrane permeability produced by bradykinin," The Journal of Trauma, vol. 29, no. 8, pp. 1053-1063, 1989.
[18] X. Montet, M. Funovics, K. Montet-Abou, R. Weissleder, and L. Josephson, "Multivalent effects of RGD peptides obtained by nanoparticle display," Journal of Medicinal Chemistry, vol. 49, no. 20, pp. 6087-6093, 2006.

[19] M.-C. Bowman, T. E. Ballard, C. J. Ackerson, D. L. Feldheim, D. M. Margolis, and C. Melander, "Inhibition of HIV fusion with multivalent gold nanoparticles," Journal of the American Chemical Society, vol. 130, no. 22, pp. 6896-6897, 2008.

[20] C. Tassa, J. L. Duffner, T. A. Lewis et al., "Binding affinity and kinetic analysis of targeted small molecule-modified nanoparticles," Bioconjugate Chemistry, vol. 21, no. 1, pp. 14-19, 2010. 

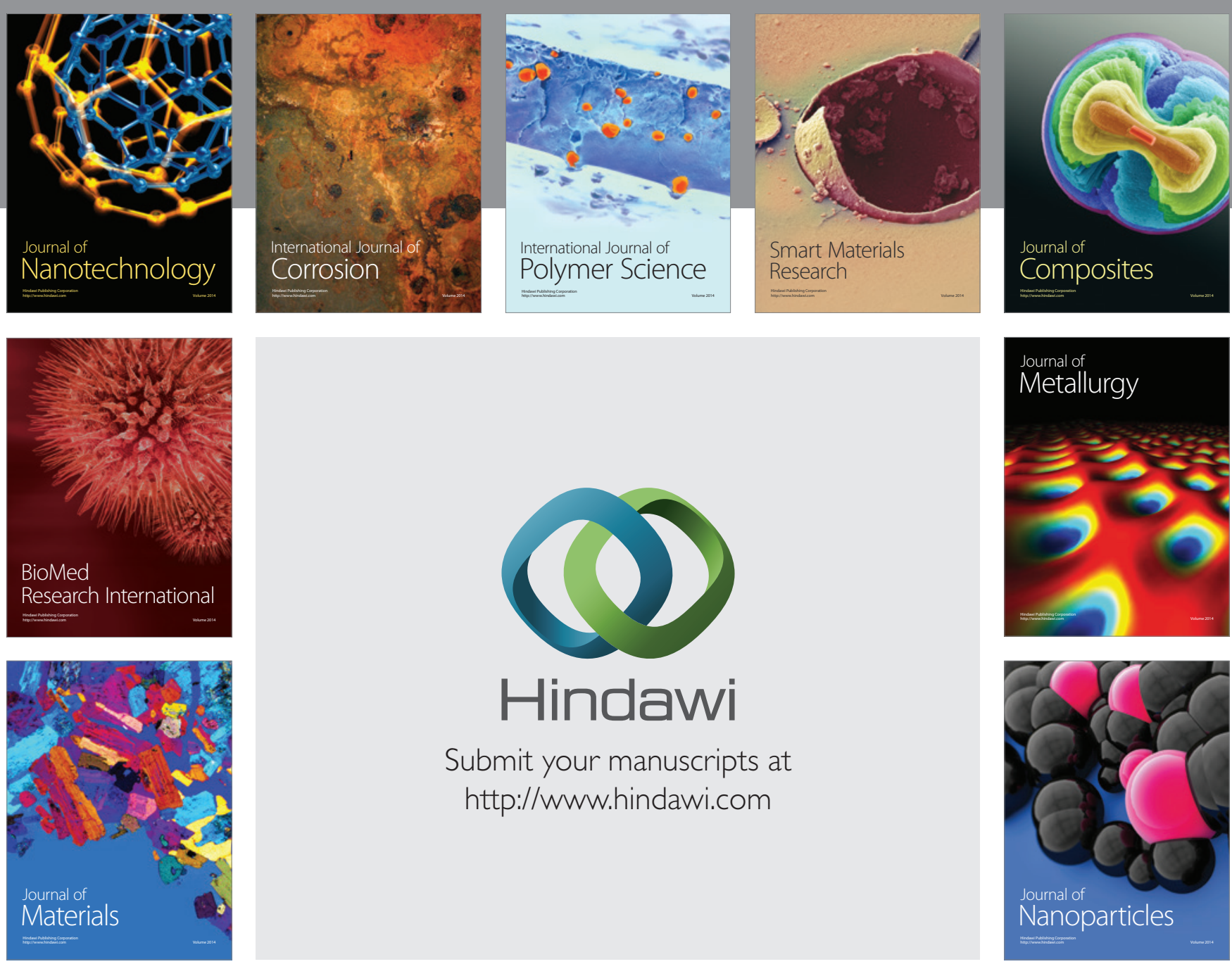

Submit your manuscripts at http://www.hindawi.com
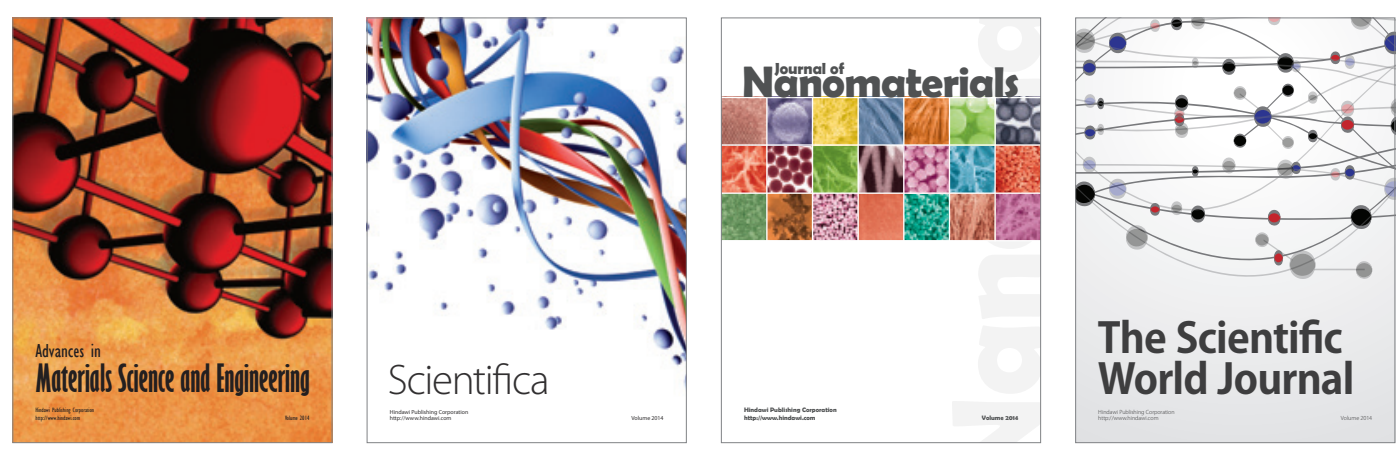

\section{The Scientific World Journal}
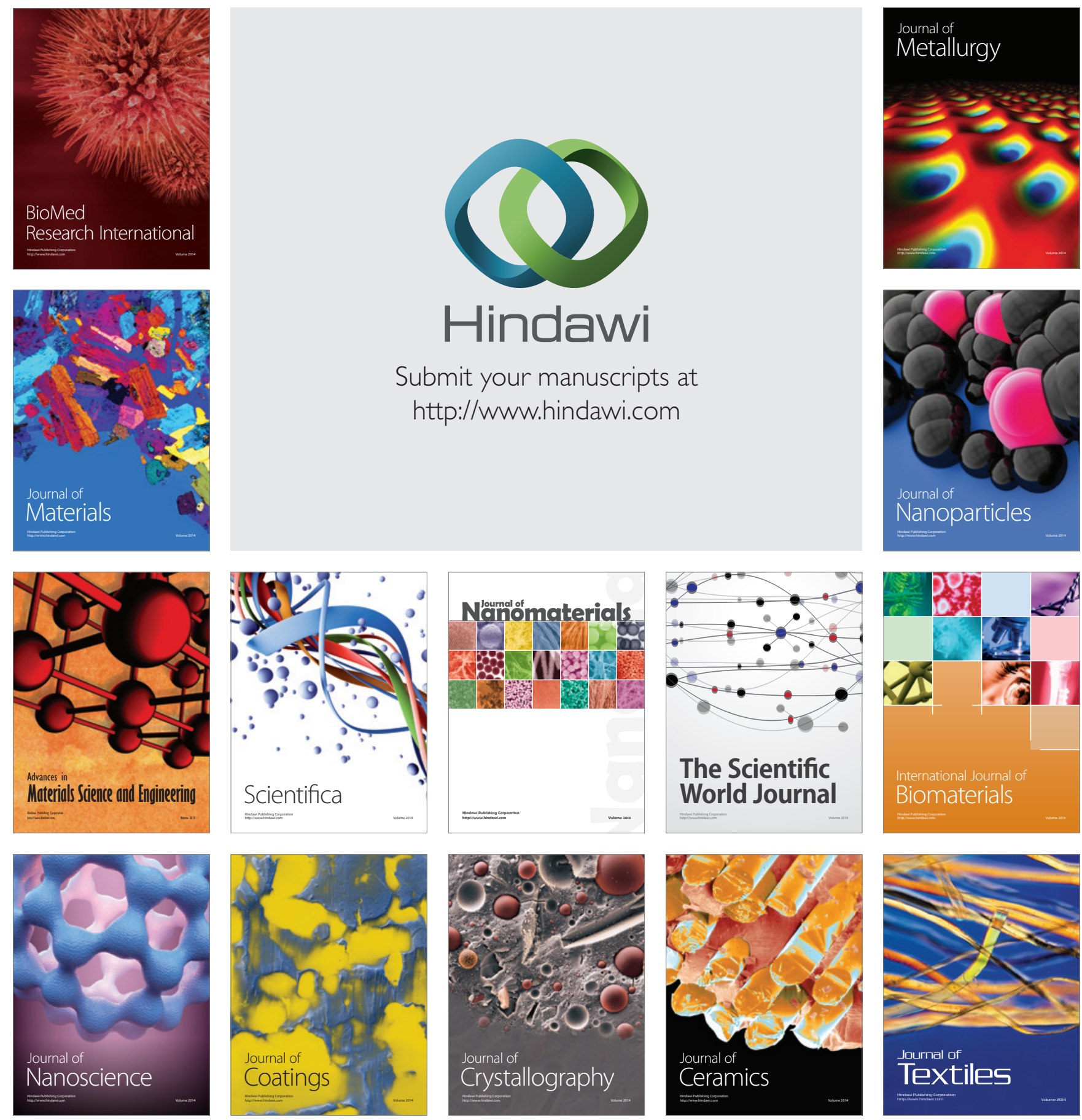